\title{
Exploration on Combinative Knowing and Doing Training Mode for Fashion Design Teaching in Universities
}

\author{
Yonggang Wang \\ Zhengzhou University of Light Industry \\ Zhengzhou, Henan, 450000
}

\begin{abstract}
The mode of training fashion talents in China can be roughly summarized as university mode and vocational school mode, the former focusing on the teaching of theoretical knowledge, while the latter emphasizing the development of skills, and each of them has advantages and disadvantages. This article starts from the exploration of how to train highquality fashion talents featuring the advantages of these two modes to meet the requirement for industrial development. The teaching idea and design practice mode of Paris Union College of Fashion may inspire us more effectively.
\end{abstract}

\section{Keywords - fashion design major; combination of knowing and doing; training mode}

\section{INTRODUCTION}

Currently, with the increased competition in fashion graduates employment, art colleges are paying an increasing attention to the development of students' practical abilities and skills for the purpose of improving students' social competitiveness through increasing the proportion of practical training in the curriculum system and implementing various forms of science and technology competitions, innovative experiments, entrepreneurial practice and other activities. These measures help change the situation to some extent where the previous undergraduate education values theory over practice, indicating that educational circles are changing towards an idea of emphasizing more on the pragmaticality. However, it should be noted that there is a serious gap between the current theoretical teaching and practical teaching in fashion design, such as scripted instruction by teachers, rote learning by students, blind experiments and so on, and it is obviously impossible for such education mode to meet the need of social development. How to handle the relation between theoretical teaching and practical teaching is an extremely urgent problem to solve for better teaching results, and the only way to solve the problem is to encourage every fashion teaching staff to understand the ideological connotation of "combination of knowing and doing" and to integrate it into the teaching process.

In Chuanxilu (literally "Sayings and Collection of Wang Yangming"), Wang Yangming discussed the relation between knowing and acting and argued that knowledge as a kind of preparation or cultivation of action, when completed, could guide action. He believed that knowledge and action were unified as one. Any knowledge that had been gained then put into action was considered delusion or false. Marxist epistemology believed that on the one hand, all human knowledge is acquired through practical activities or knowledge starts with knowledge, on the other hand, the accumulated human knowledge can guide the future practical activities for better natural and social reform. Based on this, "knowing" and "doing" are closely linked and in interaction. Teachers should keep it in mind that theory and practice are inseparable, and only through the combination of knowing and doing can we acquire genuine knowledge and implement what we have learned.

The fashion design in Chinese universities was mostly opened in the 1980s when fashion industry itself just emerged, and furthermore, China is a garment production and processing country, all of which makes our industrial development and fashion design education far behind that of developed countries. With the economic development, creative industry has attracted an increasing attention, and independently-developed and creative fashion brands under the intelligent property protection are growing rapidly. However, we tend to value the imitation of modern clothing styles originating in Europe over the research on the underlying theory and culture, resulting in the shortage of "language" for communication with each other, and then disconnecting the fashion design education from the market demand and making it difficult for our fashion brands to meet the international standards, for all of which, we fail to compete with them. Based on the author's exploration of teaching and practice, this article proposes that fashion design teaching should emphasize the importance of dress code education, and integrate design into practical operation and marketing through the setting of flexible curriculum so as to eliminate the "empty talk"-featured design and get rid of the ivory tower style training mode.

\section{A FOCUS ON THE THEORETICAL STUDY AND RESEARCH OF THE DRESS CODE}

For the teaching of modern fashion design, the author starts with the explanation of the object of study. From a broad sense, clothing refers to a variety of clothes and accessories worn by people, including our traditional 
national costumes and western costumes; from a narrow sense, it mainly refers to the modern clothing. Although the significance and charm of traditional costumes are undeniable, very few people choose to wear Han Chinese costume or Tang suit in reality except in ceremonial occasions, if any, they tend to prefer improved outfits with a Chinese-and-western style, so western clothing becomes the mainstream clothing in the popular development of modern clothing. The type of clothing worn by Chinese people is heavily dependent on the comfort consideration except the influence of mainstream culture of great powers, under this circumstance, the aesthetic standards and the underlying history and culture of western modern clothing can serve as the foundation of teaching of modern fashion design.

The dress code, also known as dress convention or dress password, is the dress norms commonly accepted by the westerners, since the norms have become more vigorous even after the development of modern clothing for more than a century and two world wars and still remains the unabated charm irrespective of complex and fast fashion life cycle, it can be called as the aesthetic standard for modern clothing. Japan's leading theoretical study of western modern clothing culture mainly benefits from 1964 Olympic Games in Tokyo, and before that, in 1963, in order to show a good national image to the people of the world, Japan Men's Fashion Unity (MFU) launched a summative study of western dress and proposed the dress TPO theory to guide Japanese citizens, and this theory has also been recognized by European and America developed countries and become popular. It does not mean that European and American countries are lack of a systematic dress theory, on the contrary, the dress code is popular among European and American countries as a systematic and mature dress theory used to popularize dress matching as a general education, or in other words, they begin to nurture the dress taste and standard from elementary education, as a matter of fact, pursuit of good dress image has become people's subconscious in European and American countries. Similarly, one of Chinese traditional classics "Three Character Classic" advocates that children should be taught that "everybody must wear their hats straight and make sure the hooks of their clothes are tied".

The basic education of fashion design starts late in our country, additionally, our elementary education does not involve the development of good dress habit. On the one hand, we fail to understand the underlying dress norms education and still focus on the protective function of clothing due to the insufficient study of western fashion culture and fashion education; on the other hand, another important reason why we dress with blind obedience is that the intensive learning and inheritance of dress culture are scarce. One can imagine how difficult it is for students who have never been exposed to the education of western clothing culture to immediately design clothes in universities where fashion design is established as a specialized course. Certainly, people may wonder that we wear modern western clothes every day, don't we? But we hardly realize that we are actually blind to the fact to which we are exposed every day, as a result, we are prone to the path of formalism. For example, if someone in a suit says hello to you on his/her own initiative in the street, your first instinct is to label him/her as a "salesman", "business manager" or the like. Why do you think it inappropriate even though the one is dressed in formal wear? For one thing, the target groups know very little about the standard for fashion aesthetic, for another thing, the wearer fails to comprehend his/her own whole dressing and simply imitates others' dressing, and the wrong tendency to define costume by jobs is the result of the incomprehension of dressing culture on both parties. Likewise, it also happens to the fashion design in many universities which start with a simple imitation of famous fashion brands in western countries irrespective of the interpretation of underlying history and culture. The creative design conducted in the absence of an understanding of standard aesthetic of fashion design is nothing but a mechanical combination of fashion elements, and such deformed mechanical combination can never grasp the essence of fashion design and definitely hinders the original design. In this respect, learning of dress code is a unbridgeable gap if we want to actually understand the aesthetic standard for fashion design and conduct creative design.

If so, how to start the learning of dress code? Firstly, to have knowledge of classic styles defined in the dress code "Fig. 1". These classic styles originate in the elegant lifestyle of British aristocracy who has taken dressing as a philosophy of life for a long time. Since all classic clothing styles reveal historical and cultural information from the whole to details, it is the key to open the password of western fashion tendency through interpreting such information in combination with historical background. Secondly, to interpret these constituent elements of each classic fashion style "Fig. 2", including standard style, standard fabric, standard color, standard collocation and TPO rules, and how to combine and modify them is the basis for us to conduct original design. 


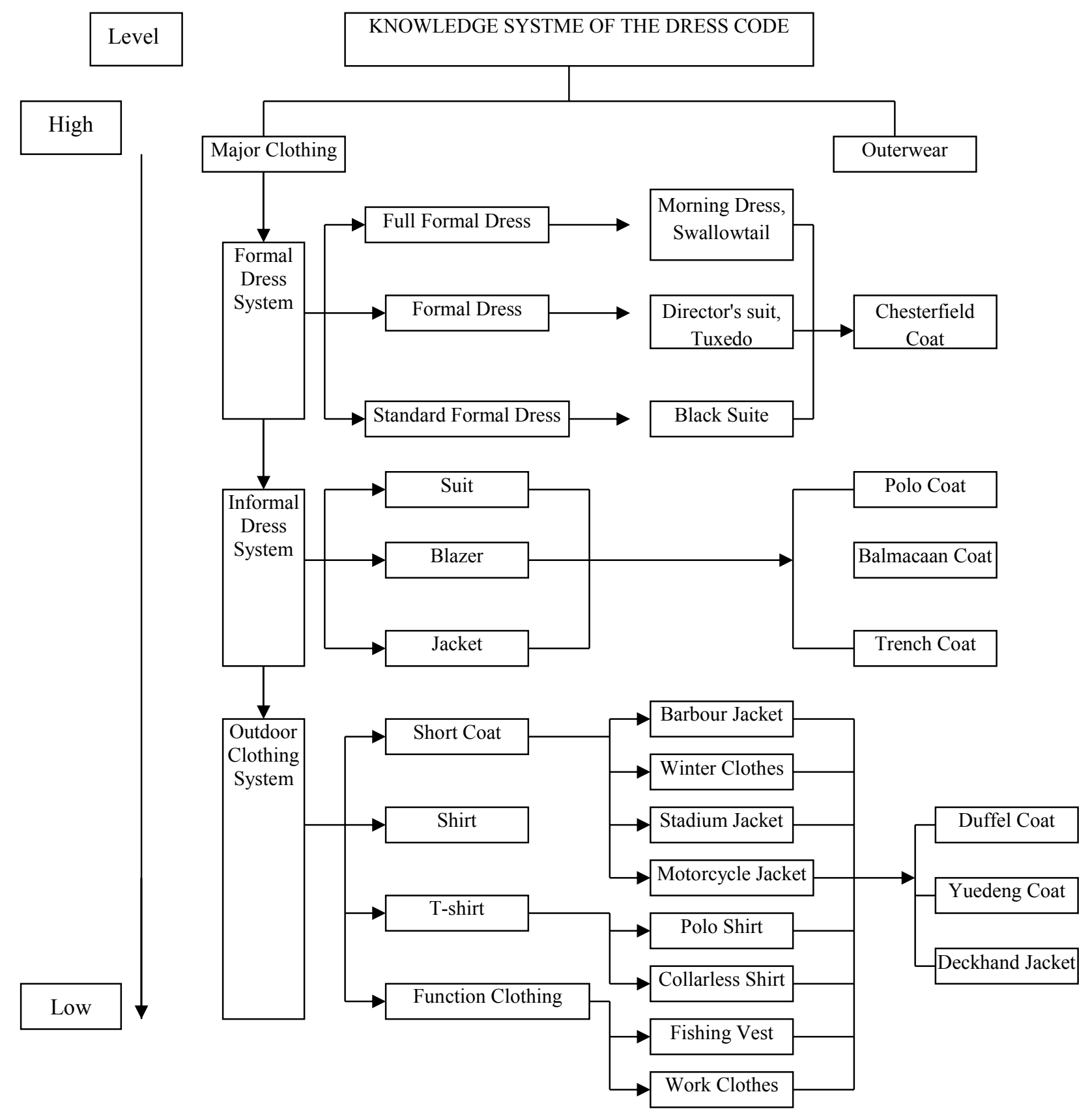

Fig. 1. Classic Styles in the Dress Code 


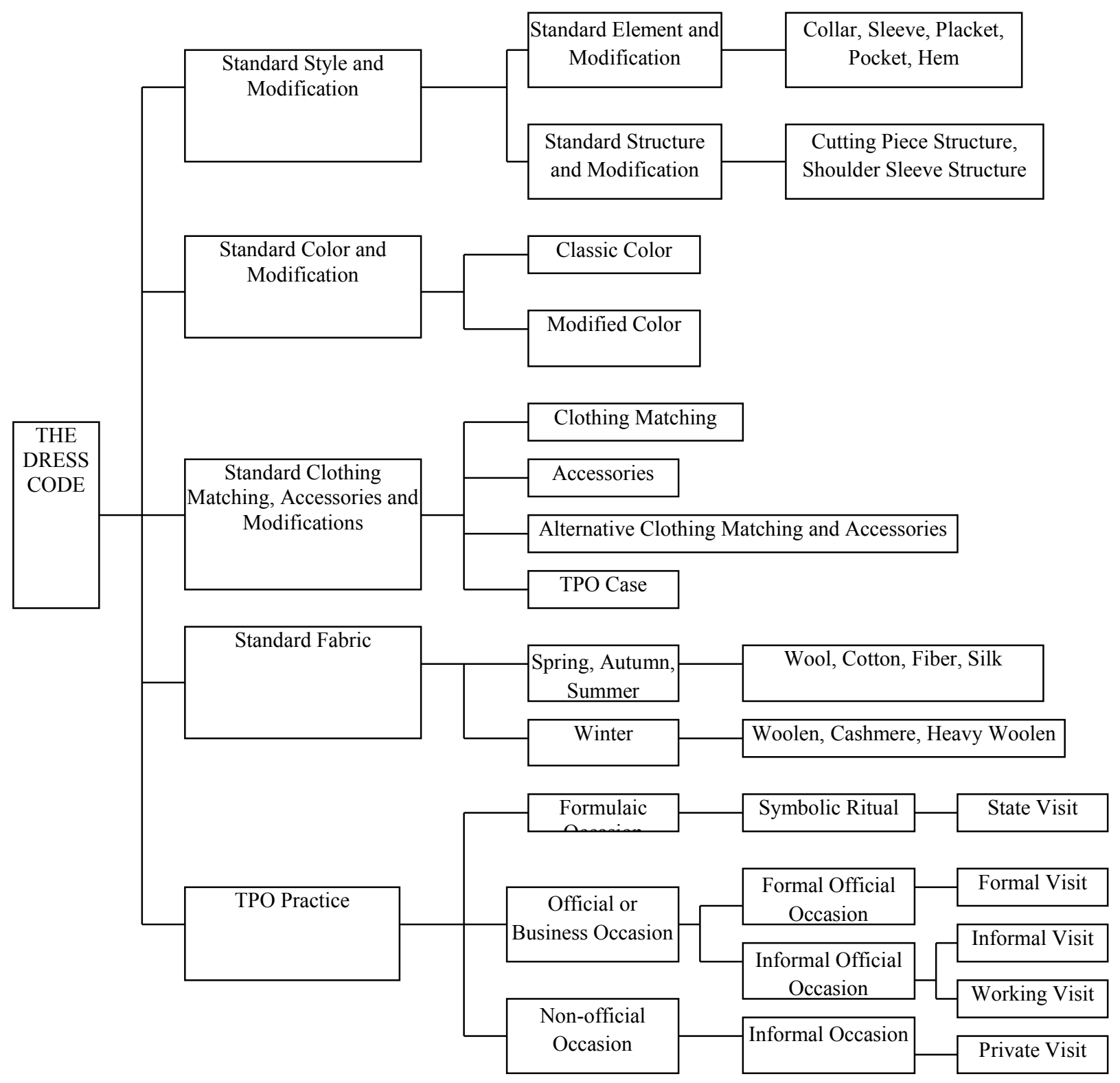

Fig. 2. Standard Elements constituting classic styles and its modifications

\section{THE SUCCESS OF FASHION EDUCATION DEPENDING ON THE EMPHASIS ON THE IMPROVEMENT OF PRACTICAL ABILITY}

China's fashion design education derives from art education and is differentiated from painting art. Nowadays, many academies of fine arts have continued the spiritual essence of fashion art design, which replenishes the development of China's fashion art with an endless artistic charm. However, the fashion industry is not only an art, but a threshold-low, labor-intensive industry which attaches great importance to handmade production, capacity and technical level, so many traditional tailors can make elegant clothes even though they know nothing about art. For students majored in fashion design, only through making clothes by themselves, can they deeply understand the meaning of combining clothing with body structure, learn the fabric performance, structural principles and production techniques from a three-dimensional perspective and then carry out a design with artistic originality from the perspective of materiality of clothing, in this way, such creative design is achievable and propagable.

Naturally, experts from many fashion colleges have declared definitely that the goal of universities and moderate speciality schools is to train students' ability to make clothes in order to establish a talent pool of fashion technology personnel in the future. Undergraduate colleges aim at the development of high-level design talents and value the aesthetic accomplishment at a higher level over the development of skills. They have no idea that high-level talents need a solid foundation of expertise more instead of 
valuing art over technology. As can be seen from graduate employment in recent years, it is obviously that fashion industry prefers technical personnel graduating from universities and moderate speciality schools, and holds a wait-and-see attitude towards high-level talents from undergraduate colleges or hires these design talents as product buyers, making it difficult for these students to display their real design abilities. We have a poor knowledge of the growth and development of talents in fashion industry after all.

Another example also reminds us of a fact that fashion design is a subject which attaches great importance on practical ability. Paris Union College of Fashion has established the teaching philosophy and practice mode of fashion design aiming at the cultivation of skills and it mainly teaches courses including design, free draping, patternmaking, DIY class, formative art, fabric design, etc. The whole teaching process featuring innovative design and practical operation encourages the cooperation with fashion brand and the close association of theoretical teaching and marketing in practice, helping improve students' teamwork and enthusiasm for learning, especially, greatly stimulate students' interest in the professional learning when they tailor and sew the clothes designed by themselves. In the contrast, our country lays more stress on the development of "academism" designers who value painting skills. Our graduates can complete excellent costume renderings in most cases, but the costume made according to the rendering is very different from the rendering, which is mainly a result of inadequate practice. The key to solve this problem is schoolenterprise integration. The Paris Union College of Fashion advocates the teaching mode in which students are required to have knowledge of the operation flow of fashion brand company in order to accustom themselves to be as a professional designer in advance, which greatly enhances students' comprehensive quality and design skills. The teaching mode of Paris Union College of Fashion indicates that our colleges which are no longer an isolated ivory tower, should not limit the fashion teaching to the campus but associate it with the enterprises. Only through the schoolenterprise integration, mutual learning and mutual reference, can the enthusiasm for and the vitality of this industry be motivated better to promote social progress.

\section{THE COMBINATION OF KNOWING AND DOING BEING A REASONABLE MODE OF DEVELOPING FASHION DESIGN TALENT}

As we all know, theory guides practice, and practice is the sole criterion for testing truth. It is unscientific if the acquisition of theoretical knowledge is not used to guide practice or practice is not used to test truth, and likewise, it applies to the cultivation of fashion design talents. In the past, fashion design in colleges highly valued the development of highly-educated and high-quality talents and overlooked the training of good skills which was supposed to be the basis for the growth of talents. There is an old saying that practice makes perfect. We fail to perfect the skills, let alone conducting ingenious design. Furthermore, our theoretical research is immature. As a branch of art, fashion design can not be disentangled itself from the art. We must admit that art has a guidance and leading role in the costume aesthetics, but we can not ignore fashion has its own unique language. The dress code, as a unique fashion language, should be the focus of the current theoretical study.

All in all, in university education, "knowing" and "doing" are always unified and inseparable. Although theory courses and practice courses can be split based on the setting of different courses, teaching method must be a combination of theory and practice. In this way, students can acquire fresh knowledge in replacement of rigid provisions, and become high-quality talents meeting the requirements for national construction.

\section{CONCLUSION}

As China's clothing enterprises are gradually transforming from a world factory offering OEM processing to innovative enterprises, fashion education undergoes a slow change. The cultivation of students' creative ability and innovative awareness has been commonly accepted by all universities and colleges. If treating the essence of fashion industry objectively, and placing an equal emphasis to the theoretical teaching and training of students' practical ability, we will have international fashion designers in the near future.

\section{REFERENCES}

[1] M. Young, The Technical Writer's Handbook. Mill Valley, CA: University Science, 1989.

[2] Liu Ruipu, "Formal Dress", Beijing, China Textile \& Apparel Press, 2002.1 (Men's Fashion Language and International Conventions)

[3] Kim John Gross \& Jeff Stone "Clothes" Butler and Tanner Ltd, Frome and London 19935

[4] Bernhard Roetzel "Gentleman" Germany 1999 for English edition

[5] Riccardo Villarosa \& Giuliano Angeli "Elegant Man- How to construct the ideal wardrobe" Random House, Inc., New York, NY. 10022

[6] Liu Qianzhou "The International Tradition for Men's Wear and the Research of Guiding Plans to the Clothes of Nation's Civil Servants" 2007326 